\title{
ROLE-MODELS OR GATEWAYS TO RESOURCES?: CONTEMPORARY CONFUSIONS IN MENTORING PRACTICE
}

\section{HEATHER TOLLAND AND MARGARET MALLOCH}

Heather Tolland is an Independent Researcher ${ }^{\prime}$ and Margaret Malloch is a Reader/Associate Professor in Criminology at the University of Stirling.

Keywords: women; mentoring; criminal justice; community support

This is the peer reviewed version of the following article: TOLLAND, H. and MALLOCH, M. (2019), Role Models or Gateways to Resources?: Contemporary Confusions in Mentoring Practice. The Howard Journal of Crime and Justice, 58: 496-512, which has been published in final form at https://doi.org/10.1111/hojo.12335. This article may be used for non-commercial purposes in accordance with Wiley Terms and Conditions for self-archiving.

${ }^{1}$ Heather conducted this research when a doctoral student at the University of Stirling. 


\begin{abstract}
Mentoring has become increasingly popular in recent years in the criminal justice system, presented across the UK and internationally as a service that can address the specific 'needs' of women. This article draws on original qualitative research with mentors and mentees to explore their experiences and to establish the aims and processes of mentoring. The rhetoric of mentoring offered by mentors and staff suggested that mentoring was based on an individualistic approach that contained responsibilising strategies. In practice, however, mentors were helping women to resolve issues related to the welfare system and other services outwith the criminal justice system. If positive outcomes of mentoring are viewed by policy makers to be the result of an individualistic approach aimed at fostering 'pro-social' interventions, rather than the result of attempts to mitigate wider structural failures then this takes responsibility away from the state and distracts from the deeper effects of criminalising processes.
\end{abstract}




\section{Background}

During the last decade, mentoring has been advocated by some policy makers and academics as an appropriate service for addressing the specific issues of women in the criminal justice system (Brown and Ross 2010; Scottish Government 2012). This paper explores the aims, goals and processes of mentoring through in-depth qualitative data which presents the views and experiences of 19 women who engaged with mentoring services in Scotland and 28 mentors and professionals. The data explores how mentoring attempts to address the issues of women who access the service and questions the extent to which mentoring offers something 'unique' and capable of addressing the profound inequalities that have contributed to the criminalisation of many women.

In 2012, a Commission on Women Offenders appointed by the Scottish Government published a report that reviewed the services available for women in the criminal justice system in Scotland and put forward a number of recommendations (Scottish Government 2012). The Commission questioned the suitability of prison for women, arguing that the issues most commonly related to women's offending could not be adequately met in custody. These issues included: higher rates of mental health problems than men; high rates of drug problems; histories of physical and sexual abuse; and responsibility for dependent children. The report also highlighted the challenges experienced post-release by women, such as securing stable accommodation and accessing benefits. The Commission made a number of recommendations that aimed to improve outcomes for women including: increased availability of supported accommodation; the establishment of community justice centres across Scotland and the availability of intensive mentoring for all women at risk of reoffending or custody. This policy recognition of the specific issues of women in the criminal justice system was not new. In England and Wales, Baroness Jean Corston's (2007) 'Review of Women with Particular Vulnerabilities in the Criminal Justice System', put forward a number of similar recommendations including: replacing female prisons with smaller custodial centres, improvements in drug rehabilitation and accommodation and reserving custodial sentences only for women who were violent and posed a threat to the public. Similarly, a number of reports have been published internationally that highlight the need for justice services to address women's complex circumstances, including 'Gendered Justice' in the United States, (Bloom, Owen and Covington 2003), 'Better Pathways' in Victoria Australia (Victoria Department of Justice 2005, 2007) and 'Creating Choices' in Canada (Correctional Services of Canada 1990, 2010). However, despite this increased focus on women in prison, numbers have continued to rise internationally. 
Although men and women who encounter the criminal justice system have experienced similar problems including issues of poverty, self-harm, family issues and victimisation, these experiences have been shown to be disproportionately high for women (Rickford 2003; Gelsthorpe, Sharpe and Roberts 2007; Scottish Government 2012; Home Office 2014). Women in prison are also more likely to have experienced emotional, physical or sexual abuse as a child compared to men, to have been victims of domestic violence as adults and to be primary caregivers of children under the age of 18 (Ministry of Justice 2012; Huebner, DeJong and Cobbina 2010).

Recognition of the importance of 'reintegrating' women into their local communities and supporting them to develop positive relationships and 'social capital'(Brown and Ross 2010) has led to a focus on mentoring. Located within criminal justice responses, mentoring has been presented as a form of support that can help women to meet the conditions of community statutory orders (Scottish Government 2012). Despite these claims, there has been limited evidence to suggest that mentoring reduces reoffending or facilitates significant changes in women's lives. There is a lack of clarity around the definition of mentoring, and how it works in practice including role definition of mentors, the extent of intensive support offered and the key aims of mentoring services. A mentor has been defined as a role model (Newburn and Shiner 2006; Bateman 2008; Trotter 2011; Scottish Government 2012), a friend (Koschmann and Peterson 2013), a 'special' type of friendship (Brown and Ross 2010) and a 'friend with boundaries' (Keating 2012). The report of the Commission on Women Offenders in Scotland, in 2012 (Scottish Government 2012: 26) defined mentoring as 'a trusted one-to-one relationship where practical and emotional support is provided by the mentor on a wide range of issues relating to offending behaviour.'

Research focusing specifically on mentoring of women in contact with the criminal justice system has noted the importance of positive relationships. Brown and Ross (2010) undertook a qualitative approach with women leaving prison in Australia and their mentors. Mentors built relationships with women inside prison and continued to meet for several months after release. The mentor provided a range of services including: driving the mentee to appointments, assisting in the completion of job applications, accompanying women on shopping trips and going for coffee. Brown and Ross (2010) reported that many of the women interviewed had rarely experienced a positive relationship before, and gained confidence and self-belief through engaging with a mentor. It is not clear whether increases in 
confidence and self-belief were associated with changes in circumstances in the lives of women (that the mentor may have facilitated) or due directly to the emotional support of the mentor. Mentoring provided beneficial support to a small number of women who engaged with the service, however many of the women who initially signed up for mentoring never attended any appointments and women with less severe drug and alcohol problems and fewer offences were more likely to engage. This raises questions about the suitability of mentoring for those women in the criminal justice system who have more serious drug and alcohol offences, significant histories of offending and may be most in need of support.

The high attrition rate of mentoring was also found in a study based in Scotland in 2015 (Ipsos Mori 2015). Of 418 mentoring referrals, 38\% had not engaged with a mentor and of the remaining $62 \%$, the majority had engaged for just two months or less. This study by Ipsos MORI (2015) was part of a wider evaluation which included all mentoring schemes for women and mentoring schemes for 'prolific' young male offenders in Scotland (Mulholland et al. 2016). Mentoring could include all or any of the following: one-to-one meetings with their mentors; practical support such as accompanying mentees to other agencies; help with producing CVs and groupwork. Sign-posting to other agencies was a common aspect of mentoring with $74 \%$ of mentees being referred onwards. These agencies provided: financial assistance; drug/alcohol services; employment/education; healthcare and accommodation. The wider evaluation showed that of those who engaged with mentoring for five months or longer, just over $50 \%$ made progress on at least one outcome. This implies that under half of mentees did not make any progress on any outcome after five months, suggesting that mentoring may not be beneficial for a significant number of those people referred to the service, alternatively it may reflect limitations with the evaluation tools.

Although mentoring services have been directed towards women, it is not clear what makes mentoring, as an intervention, unique or effective in responding to the structural difficulties that have contributed to many women's involvement in the criminal justice system. The majority of mentoring services referred to in existing literature focus on relationships and attitudes, and this approach has been criticised by some scholars for relying on an individualised framework that neither challenges nor accounts for the circumstances that precipitate women through the criminal justice system (Pollack 2005; Godkind 2005, 2009; Hannah-Moffat 2010). An individualistic framework is evident in services that emphasise the importance of outcomes in terms of building confidence, self-esteem and empowerment 
with less consideration of circumstances and context; possibly a reflection of organisational remit rather than intent. These frameworks reflect strategies that aim to put the responsibility onto women for their own circumstances such as 'crime' but also wider experiences of poverty. Pollack (2005), drawing on the concept of responsibilisation, states that those who offend are viewed as having failed at their own 'selfreform' and require support to become responsible and moral citizens.

A UK based study by Corcoran and Fox (2013) demonstrated how services that claim to be based on the needs of women, taking into account their structural disadvantage, can contain incompatible underlying theoretical assumptions. In their review of an evaluation of the Release Programme in the UK, the authors explored whether community based sentences were in practice 'innovative' approaches to working with women. The Release Programme was a 'one-stop shop' directed towards women leaving prison, women with a criminal record or those perceived as at risk of offending. Activities at the centre included one-to-one meetings with workers and group work. Staff in the study expressed contradictory rationales for providing support to women. For example, the staff highlighted the personal responsibility of women and the importance of empowerment, but conversely they also emphasised the welfare needs of the women they worked with. Corcoran and Fox (2013) also found that workers utilised discretionary practices due to the unrealistic nature of official objectives. Drawing on governmentality theory, the authors questioned whether community based sentences were similar 'technologies of governance' to those present in the prison environment. The authors suggested that the perception of community sentences as innovative may be misleading as they actually increase the number of women being criminalised and under state control through this 'governing at a distance'.

Services developed specifically for women in the criminal justice system in Scotland have also been shown to be limited in scope due to their location in the penal system. The 218 service in Glasgow, a residential and community support for women in contact with the criminal justice system, has shown positive outcomes for the women it has supported, including decreased drug and/or alcohol use and improvements in health and wellbeing (Malloch, McIvor, and Loucks 2008; Easton and Matthews, 2010).However, the location of this service in the criminal justice system with statutory funding resulted in an increasing focus on criminal justice objectives as the service progressed, as opposed to the original focus on prevention, safety, connection and loss. During 218's first year, the women who were referred were viewed as 'at risk' of reoffending in the long-term and in this way the service was viewed as 
preventative. However, as the service became better known, it was increasingly viewed more as a resource for the criminal justice system rather than a primarily preventative measure and the number of self-referrals and referrals from welfare related agencies decreased (Malloch, McIvor, and Loucks 2008).

The Women in Focus service was a resource introduced to provide innovative and intensive support for women in the criminal justice system in one area of Scotland, showing positive outcomes for women such as improvements in housing; safety improvements related to domestic abuse; increased access to benefits and health services; increased confidence, and reductions in reoffending (Burgess, Malloch and McIvor 2011). However, evaluation of the service (Burgess et al, 2011) highlighted the impact of poverty, addiction and deprivation experienced by many women accessing the service, which was limited in its focus to helping women 'cope'. Again, this is reflective of the realistic remits that services work to and the inability of services located in a criminal justice context to significantly impact on circumstances of women when they have no power to make radical changes to social policy. This is particularly difficult in Scotland where, despite some devolved powers to the Scottish Government, the main responsibilities for social security and welfare policy remain with Westminster.

\section{Methodology}

This study draws on data from a doctoral study that included interviews with 52 individuals involved with a mentoring service in Scotland. In-depth semi-structured interviews were carried out with 19 women who accessed a mentoring service specifically for women, 14 mentors (including 3 volunteer mentors), 9 social work professionals who made referrals to the service and 5 managers from the organisation that provided mentoring ${ }^{2}$. Participants were accessed via official approval from the mentoring organisation and following this, contact with various members of staff who acted as gatekeepers. This study was focused on the characteristics and operations of the mentoring schemes and how this related to the circumstances of the women who engaged with the mentoring service. Criteria for accessing the service was targeted towards women who were subject to a statutory order or had recently left prison. A key aim of the service was to contribute to an overall reduction in reoffending by increasing women's self-confidence, self-esteem and engagement with agencies that, it was anticipated, would assist in their resettlement. Women were offered practical and emotional support from a mentor on a one-to-one basis through weekly appointments. The majority of mentors were paid members of staff with a professional background in support work. A small

\footnotetext{
2 This mentoring service also co-funded the doctoral study.
} 
number of volunteer mentors, also contributed to the service. Volunteers tended to be university students looking to gain experience in the criminal justice sector.

Semi-structured, face to face, individual interviews were selected as the main data collection tool; the approach used with all participants. Methodologically, a feminist approach was adopted which focused on and prioritised the accounts of women in the criminal justice system, underpinning the study with a consideration of gender in the research questions and analysis (Oakley 1981). The interviews explored women's own experience of mentoring, the definition of mentoring and the impact of the service. Interviews were carried out in the office locations of the mentoring service as it was important that the women who were participating in the study were in an environment where they felt safe, and where they had the support of a professional that they knew should they need it. In addition, interviews with mentors and other stakeholders focused on experiences of mentoring sessions, mentoring activities, training and perceptions of the outcomes of mentoring. All interviews were audio recorded and fully transcribed with the consent of participants. A thematic analysis was employed, in line with the process of data analysis described by Strauss (1987) which involves the three stages of open coding, axial coding and selective coding. Data was stored and organised using the computer-assisted qualitative data analysis software (CAQDAS) NVivo 10. Full ethical approval was obtained before commencing the study.

\section{Findings}

\section{Characteristics of women}

Life experiences of poverty, addiction and trauma were common among women who accessed the mentoring service. Mentees ranged in age from 22 to 56 years old. All of the women who participated in this study were unemployed and the majority had limited education or recent employment experience. Consequently, financial difficulties, problems with drug and alcohol use and health concerns were prevalent in the lives of participants:

${ }^{3}$ Claire: So basically I was serving a prison sentence and was going to come out of prison with no clothes, no place to stay and with no money, with no funds, so that was a huge fear to step through the gates.

\footnotetext{
${ }^{3}$ All participants were anonymised with women who used the service given pseudonyms.
} 
Gemma: The days consist of trailing around looking for the shops which are inexpensive, balancing heating and food costs [...] I find it exhausting at times to be honest, trailing shops and soul destroying, standing at bus stops and absolutely frozen...having been fed up in the first place.

It was also evident in the accounts of women, that they rarely had any family or friends that they could rely on for financial support:

Barbara: I've got no immediate family so it's not like I can get help from them so I really do need to start tightening the old belt buckle and saying like, enough's enough. Let's get this sorted.

All of the women in this study had been convicted of at least one offence, with the majority having more than one conviction. Offences were typically related to drug and alcohol use and included breach of the peace and shoplifting. A high proportion of women outlined their experiences of social isolation. Many had been separated from their children who were 'in care'. Women commonly reported experiencing depression and anxiety with some reporting the use of drugs or alcohol when they felt distressed:

Christine: I used to take heroin. I don't take heroin anymore but occasionally what I do is take crack cocaine but that's just occasionally. I've not got a habit with it but I have got an addictive nature and I still do drink but not as much... That's a lot to do with my mood. If I'm feeling depressed instead of killing myself, I'll take a drink to stop me from feeling that way.

Linda: Now I went through a year with this [waiting on] trial and I didn't think of drink or drugs thank god. Then one day I got a letter in saying my money had been cut and that night I thought 'I'm better off on drink and drugs'... but thank god the feeling does pass.

Some women also reported feelings of shame and stigmatisation related to criminal convictions and subsequent social marginalisation. The characteristics of the women who accessed the mentoring service reflected those of women generally in the criminal justice system who had experienced disadvantage throughout their lives (Gelsthorpe, Sharpe and Roberts 2007; Baldry 2010).

\section{Definition of mentoring}

It was clear that mentors had difficulty defining mentoring as a concept and also what was involved in the role: 


\begin{abstract}
Mentor 4': It's got lots of different meanings. It's changed a lot recently but it's a lot bigger recently after Elish Angiolini and the [Scottish Government] Commission report and things like that. From when I started as a mentor, the word mentor didn't ever really mean much. It was just another word for a worker... Now mentoring is massive and it's a proper word and properly means something... You could really put it into a lot of things but definitely one to one, it's intensive and I would say that role modelling would be a massive element to it.
\end{abstract}

Mentor 4 highlighted how the label of 'mentor' has become important due to the increasing popularity of mentoring in the criminal justice sector. Definitions offered by women who had engaged with a mentor highlighted the relational aspects of the support. Advice, encouragement and support defined the role of a mentor, similar to a befriending role, where the focus was on building a relationship and reducing social isolation (Scottish Mentoring Network 2016):

Jacqui: Someone that is there to advise you and help you out and gab away to you and things like that. Letting you know what help is there for you. Like housing issues and even addictions, training courses.

Mentors have increasingly been defined as 'role models' (Newburn and Shiner 2006; Bateman 2008; Trotter 2011; Scottish Government 2012) emphasising the expectations for individual change that are expected of women who engage with mentoring services. However, women who used this mentoring service did not describe their mentor as a role model, but often as a 'friend':

Christine: I don't even see it as a support worker, I see it like it's...my best pal. That's what it's like. My best pal. Because you become close and you get to know each other.

For some women, the relationship with their mentor was 'like a friendship' rather than being a 'real' friendship, suggesting that they understood that their relationship had boundaries. This is in line with previous research where women in prison who were paired with a mentor viewed them as friend with boundaries and did not describe their mentors as role models (Brown and Ross 2010; Keating 2012).

The perception of mentors as 'friend' rather than a 'role-model' may also reflect the significance of social isolation as a key issue for many women rather than a deficit of social skills. Indeed women

\footnotetext{
${ }^{4}$ Mentors and other staff are represented by their job title while women who used the service were allocated a pseudonym to maintain the personal aspect of their accounts. We appreciate the disparity of this approach but have used it in order to prioritise the voices of the women accessing the service and to indicate the role of the participants in relation to the service provided.
} 
emphasised the importance they placed on having someone to talk to about their concerns. In contrast, mentors and social workers were more likely to describe their support as 'role modelling', highlighting a discrepancy between the women's and mentors perceptions of the basis of mentoring.

\section{Aims and purpose of mentoring}

Accounts from mentors differed from women's accounts when they spoke about working towards goals related to the development of skills and confidence. Mentors were more likely to relate overall aims of mentoring to changes in behaviour and attitudes than the women who used the service. Some mentors spoke about helping the woman to make better choices, or helping the woman to become a responsible citizen and exhibiting socially acceptable behaviours:

\section{Manager 5: The long-term ultimate outcome is for women to stay out of trouble so to reduce reoffending to get on with their lives, to be responsible citizens.}

Mentor 5: Ultimately it's hoping that their lives can be offence free, stay out of prison, socially acceptable behaviours and good relationships in their community.

According to mentors and social workers a key aim of mentoring was the improvement of a range of skills including social skills, life skills, decision-making skills and the 'skills to trust somebody.' Although women who used the service generally did not talk about their offending as a consequence of bad decision making, some accounts from staff indicated that there was a belief that women had made the 'wrong' choice and mentors aimed to give women information that would lead to 'better' choices:

Mentor 2: I see myself as someone that has life experiences and local knowledge of llocal areal and of other services and would share that with an individual so that they have as much of an informed choice...everybody has the right to live the life that they choose and as long as they've got the information given then they can give an informed choice.

Mentors suggested that one of their roles was to influence the decision making skills of the women they worked with. This focus on individual choice combined with an understanding of the difficult circumstances in the lives of the women may reflect the inability of the mentoring service to address these structural issues outside of the criminal justice system. This is consistent with the research by Corcoran and Fox (2013) who highlighted incompatible theoretical underpinnings in workers' perceptions and practices. The language used by mentors and workers reflected that of an individualised approach: 
Mentor 5: Empower them to make better choices and better relationships and improve their social skills so that they're better equipped to lead a non-offending existence.

Social Worker 7: What I would hope to see is that a person who has been mentored comes out of the process more competent with improved capacity to problem solve and deal with day to day life issues...It's a horrible word but 'pro-socially'so that they're dealing productively with the benefits agency and getting the outcome that they need without break down, without running out the door and disengaging.

This language of 'empowerment' and 'life skills' has been located within 'responsibilising' strategies (Hannah-Moffat and Innocente 2013). Rather than viewing external circumstances and poverty as the key cause of women's disadvantage and subsequent offending and thus of mentoring intervention, these accounts from mentors suggest that women's disadvantage is primarily attributable to their lack of skills; or perhaps this is the only level at which mentoring can have impact.

\section{Mentoring in Practice}

The activities most frequently mentioned by women who used the mentoring service reflected short-term goals: accompaniment to appointments; referral to other agencies; setting up benefits and 'having a chat'. Other activities included: budget plans; making phone calls; teaching new skills (e.g. form filling, talking on the telephone to agencies, CV writing); and speaking on behalf of the woman to other agencies. Practical support was a key component of the mentoring relationship, especially when a woman was leaving prison and the mentor met her at the prison gate, as described by two women here:

Stephanie: She also made arrangements to meet me on the day of my release Ifrom prison] and also she was in contact with other agencies [...] she was in close contact with the lady who has the house so she made the arrangements to meet someone who was going to hand over the keys [for my accommodation] She had contacts with another agency, to take me somewhere they give people second hand clothes....and even on the same day amazingly she had made arrangements for me to have food parcels. Honestly all in the same day. All that happened like in a dream.

Claire: Because you only get a liberation grant /when you leave prison], it's not very much money and then you've got...all the running about to do and that's when most people after maybe phoning up the benefits agency four or five times in the one day end up hanging up the phone and walking and shop lifting after drinking. They start reoffending again because things... I mean things are hard for everybody now, even people that are out there working or bringing in a wage, things are hard. 
Mentors and social work staff stated that the provision of practical support facilitated the building of a trusting relationship. Mentors generally stated that the two most important practical issues that they supported women with were housing and benefit payments and applications. Support with housing was more common with women who had recently left prison. The following quote suggests that accommodation can be so scarce in some areas of the country that 'any' accommodation is viewed as a positive outcome:

Mentor 11: So homelessness is quite high for the women. But it's good that because we're part of the women offenders' team, we have a housing officer that we can phone and say 'right one of our women is coming out of prison, or is homeless, can you get me accommodation?' She'll get you accommodation that day [.../ It might just be a $\mathbf{B} \& \mathbf{B}$ but it's something to give them a roof over their head.

However, one mentor and one social worker stated that certain accommodation on offer to women was unsafe, and they understood that prison would be perceived by women in these circumstances to be a preferable environment. By unsafe they generally meant that women with addictions would be surrounded by other individuals using drugs and alcohol, making it difficult for them to avoid substance use in that environment. The quality of accommodation on offer is described by mentee Alana:

Yeah, me, [my mentor] and my housing officer are trying to get me into a scatter flat [temporary accommodation] where it's just for me but there's a waiting list and it's pretty tight just now but it would be good if I could get my own scatter flat, because like I've had people that stay there - drug users, using on the premises, stealing my clothes, stealing my make-up, stealing my converse trainers and my shorts, skirts, everything.

This should be considered in the context of a high demand for temporary accommodation in Scotland, where approximately 10,000 households are classed as temporary (Scottish Government 2014).

Support with alcohol and drug use was also seen to be vital, for example, if the woman was not already in receipt of an opiate substitute then the mentor would attempt to fast track this process where possible using their own contacts.

Mentors also related this practical support to skills development. Some mentors stated that they would practice scenarios with a woman, then encourage her to undertake these tasks on her own: 
Mentor 9: So there's a lot of women 'oh I've got this letter and there's a phone number and oh I canny phone.' That's fine, I'll phone, that's fine. It's the simplest things like that can stress a woman out because they haven't got the confidence and they feel they don't have the right words that they can use to phone up and say 'such and such has got an appointment, she's not quite sure where it is or what time it's at, can you confirm that?'...So it's about identifying their weaknesses and strengths and using that to work on the different areas that are there.

This approach was also reflected when mentors described situations in which they aimed to improve the social skills of the women they were working with. The following is a comment from a mentor on the lack of appropriate communication skills of the woman in a meeting with an external agency:

Mentor 4: They always like us there [meetings with agencies] because it's someone to sit beside them, to fight their corner. Quite often you'll get them looking at you as if 'I don't know what they're saying' and you can explain it in a different way to them because you know your girl a lot better. You know what she understands, you know where she's coming from and a lot of the time they can't verbalise that. Whether they just physically can't do it, that they don't know how, or they get intimidated or that but sometimes I'll speak on their behalf.

Emotional support was viewed as being equally as important as practical support by the majority of mentors, workers and women who used the service. Mentors were able to assist women who experienced anxiety, to leave the house and attend appointments, for example, at the job centre, General Practitioners' surgery, counselling services, court or the social work offices.

Some of the women stated that they felt comfortable confiding in their mentor about situations they were reluctant to share with family/friends or where they indicated that they may not have anyone else to confide in:

Diane: So you feel as if you've got that other side to the fact that it's professional, where you're having a trusting friendly chat with somebody when you actually need to have it because you've been keeping it to yourself or you've had nobody to talk to.

Emotional support was also evident in situations where mentors had gone beyond their mentoring role:

Mentor 5: She'd been hospitalised over Christmas and I had been going into see her. I was the only person going into see her over Christmas so for her that was obviously quite a big thing. 
This 'extra mile' support suggests that mentoring is flexible however, this of type support is difficult to define and may be inconsistent between organisations and mentoring relationships. Therefore, policy may fail to take account of this 'extra-mile' support as a component of mentoring.

\title{
Disengagement and exit from mentoring
}

Although it was common for women to miss scheduled appointments with mentors, a number of mentors stated that very few of the women they worked with had disengaged completely from the service and even if they did not engage for a period, they would normally meet with the mentor again after this break from contact. Other mentors and staff stated that disengagement was a problem and there were a number of possible reasons for this. Women who were viewed as 'not ready' to benefit from mentoring were those who were perceived to be heavily using drugs or alcohol, in unstable accommodation and therefore unlikely to keep mentoring appointments. 'Low mood' or 'self-esteem' was also viewed as preventing effective engagement with a mentor. Personal relationships were also identified as being a substantial barrier to engagement, as noted by a manager:

\begin{abstract}
Manager 1: We can start engaging with a woman and she's on her own and then six months down the line she meets someone and new issues occur, so for that reason again you would hope that you could continue to support and continue to build their self-esteem but their needs are such that we're not able to meet them. And they look for them elsewhere and that's not always the positive influence that you would want them to have.
\end{abstract}

Women who used the service agreed that sometimes women might be too 'chaotic' to engage. For example, they might be heavily abusing drugs or alcohol and/or be experiencing an abusive relationship, and therefore unable to engage with a mentor. Women also suggested that others might not engage in mentoring because they were worried about being 'let down', or concerned that information disclosed to the mentor may be reported to social work and result in negative consequences, such as increased monitoring of their relationship with their children or having their children removed from their care. This raises questions about the confidentiality of the mentoring relationship, when the organisation has close contact with statutory funders. 


\title{
Exit from mentoring
}

The majority of mentors could not identify an established length of time for the mentoring relationship, stating that it varied depending on the needs of the woman. Of those who engaged with the service and participated in the interviews, the length of the relationship had varied from one to thirteen months with an average length of relationship of seven months. Many of the women the mentors worked with had been in contact with the criminal justice system for many years, as one mentor explained:

\begin{abstract}
Mentor 7: Some of the women I'm working with are in their 40s or 50s, some in their early 20s. It's taken a long time for them to get where they are when they're referred to us [...] I think because it's taken them so long to get where they are, six months is not going to magically change things around. It's not.
\end{abstract}

This suggests that mentoring may be more beneficial for women if they can engage on and off for a significant period. One mentor noted that the mentoring service she worked in had changed funding streams and this had affected the resource she could offer:

Mentor 6: So January last year to June [.../ I had to close [cases of] women because they weren't applicable for the new lfundingl criteria. A couple of them, it was difficult because...there wasn't really many services [for them]... So a couple of women they did find it difficult and they did say that to me that they didn't want to leave the service and they wish they were eligible.

It was clear that the mentoring service was operating within funding constraints. This is in line with the increasing problems of limited funding and competition between organisations for funding. Closure appeared to be outwith the organisation's control and was often the result of funding constraints, suggesting that the close alignment with the government had resulted in the organisation losing their critical 'voice' to an extent. Stacey (2012) argues that it is difficult for organisations to make the needs of their 'clients' the focus of their service when there is competition for funding, and the best value for money is being prioritised.

When the decision was made to end a mentoring relationship, mentors stated that this was discussed in advance to prepare the woman for the reduction in support. The woman was sometimes allocated a volunteer mentor dependant on whether she wanted continued support and the availability of volunteer mentors. On occasions there were 'unplanned exits' where the woman would stop engaging with the mentor once her needs had been met and the relationship came to a natural end. There were 
instances where women disengaged and the mentor failed at attempts to make contact with the woman. If no contact was made after several attempts by the mentor, then the service was withdrawn.

\section{Discussion}

Findings revealed that mentoring was difficult to define for both women who were mentored and mentors. Many mentors and other workers viewed mentoring as role modelling, however, women who accessed the service were more likely to view their mentor as a friend and 'someone to talk to' suggesting that the relationship was not an opportunity for women to model the behaviours of their mentor, but as emotional support and a release from their social isolation. Mentors also perceived mentoring to encompass any type of support that a woman needed. Although this understanding and practice of mentoring may be beneficial in its flexibility, it has potentially problematic implications for policy and practice in that mentoring that encompasses a range of interventions could be difficult to replicate.

Practical support provided by the mentor was crucial for helping women to respond to difficulties related to poverty, which reflected deficiencies in the welfare system. This included helping women to access benefit payments or taking women to appointments. Emotional support was provided via home visits, social outings, or through talking on route to an appointment. Appointments sometimes consisted of a 'chat' between the mentor and woman, and in this way the mentoring role was akin to a befriending role.

The formal rhetoric of mentoring offered by mentors and workers suggested that mentoring was based on an individualistic approach that contained responsibilising strategies, aimed at helping women to make improved choices and become responsible citizens. In practice, however, mentors helped women to resolve issues related to the welfare system and other services outwith the criminal justice system. Empowerment, reduced reoffending and responsibility were identified as key goals of mentoring. The findings from this study supports the research by Pollack (2005) that services designed for women in recent years are at least partly focused on the goal of becoming a 'responsible citizen.'

The focus on individual behaviour and attitudes by mentors when they discussed the goals of mentoring, combined with the empathy and understanding expressed about the circumstances of women, supports the research by Corcoran and Fox (2013) who also identified some inconsistency in 
worker perceptions. Similar to the research by Corcoran and Fox (2013), although mentoring was advocated as an innovative service in that it met the specific needs of women, there were underlying assumptions that attributed responsibility for disadvantage onto the individual. In this sense, mentoring was similar to other services in the criminal justice system that focus on behaviour and attitudes and fail to challenge the structural barrier of poverty.

Although there were many women who disengaged with mentoring, it was not possible to contact those women for this study. In order to meet the requirements of ethical approval, it was necessary that women were contacted via mentoring service employees, and those who did not have a positive experience with the service may have not have been contactable. Workers may have decided not to contact specific women who they expected to offer criticism of the service. Thus future research would benefit from the inclusion of input from women who disengaged with mentoring at an early stage.

The women in this study valued their mentoring relationships and offered little criticism of the service. Some women may have been reluctant to criticise the service because they did not want it to reflect badly on their mentor with whom they shared a good relationship. However, it remains that women spoke extremely positively about mentoring and favoured it over other services that they had encountered. They benefitted significantly from the intensive support that mentors were able to offer.

The mentoring service that is the focus of this study received funding from the Scottish Government and statutory sector. The service was therefore focused on the priorities and objectives of the government and often characterised by short-term funding. The short-term nature and uncertainty of future funding can prevent organisations from developing innovative services or making radical changes to their service, due to concerns about sustained resources. Funding for third sector organisations in criminal justice is becoming more competitive at a time when cuts to services outside of the criminal justice system are entrenched, for example, reduced resources for the welfare system. As these cuts are likely to send women further into poverty, they will have a direct impact on the service that mentors are expected to provide.

The importance of 'mentoring' has increased in Scotland due to the recommendations of the report of the Commission on Women Offenders, and internationally; potentially related to the increasing 
marketisation of third sector services. Recent funding has been directed towards mentoring, and therefore in an environment where resources are limited, services are more likely to be supported if they can offer a service that is favoured by funding bodies i.e. the Scottish Government in this case.

Through critically engaging with mentoring, this study found that the structure of mentoring aligned with models of self-reform and responsibility which have been evident in other services for women in the criminal justice system. However, this study has highlighted the contradiction between practical responses to welfare needs and the incompatibility of this with theories of mentoring focused on selfreform and responsibilisation. This study raises questions about the uniqueness of the mentoring service and its inability to challenge the circumstances of poverty, addiction and experiences of abuse in women's lives that had contributed to their criminalisation. The mentoring service was located in the criminal justice system, focused on repairing the harm caused by women's marginalisation and subsequent imprisonment. However, while women are located within the criminal justice context this necessarily prioritises a focus on individual deficits.

Through uncovering and prioritising the beliefs of women who use the service and exploring the accounts of workers, the findings of this study suggested that although the rhetoric of mentoring was one that implied that mentoring was an individualistic approach, in practice a substantial component of mentoring was concerned with mentors trying to 'fix' problems outwith the criminal justice system, highlighting the need for wider policy change to implement significant changes in the lives of women that take account of the social issues that many women face. As mentoring becomes an increasingly popular 'go to' solution within criminal justice systems internationally, it is important that the disjuncture between rhetoric and reality identified in this study is acknowledged and addressed. Mentoring was useful, in many circumstances, to provide a safety net both emotionally and practically, for women who were very often in dire situations. Emotional support to offset isolation, practical support to address economic and social disadvantage meant that mentors were greatly appreciated by the women in this study. These findings have significant implications for the future development of services for women, exposing as they do, the deeper and more pervasive structural social and economic problems that underpin processes of criminalisation and the need to challenge, rather than to shore up, the harms of social injustice. 


\section{References}

Baldry, E. (2010) 'Women in Transition: From Prison to....',Current in Issues Criminal Justice 22(2), 253-268.

Bateman, T. (2008) Review of provision for girls in custody to reduce reoffending, Reading: CfBT Education Trust. Available

at: https:/www.educationdevelopmenttrust.com/ /media/cfbtcorporate/files/research/2008/r-review-ofprovision-for-girls-in-custodv-to-reduce-re-offending-2008.pdf (accessed:18 February 2014).

Bloom, B., Owen, B.A. and Covington, S. (2003) Gender-responsive strategies: Research, practice, and guiding principles for women offenders, Washington, DC: National Institute of Corrections. Available at: https://nicic.gov/gender-responsive-strategies-research-practice-and-guiding-principles-womenoffenders (accessed: 10 November 2018).

Brown, M. and Ross, S. (2010) 'Mentoring, social capital and desistance: a study of women released from prison', Australian \& New Zealand Journal of Criminology 43(1), 31-50.

Burgess, C., Malloch, M. and McIvor, G. (2011) Women in Focus: an evaluation, Glasgow: The Scottish Centre for Crime and Justice Research. Available at https://www.sccjr.ac.uk/publications/women-in-focus-an-evaluation/ (accessed: 10 November 2018).

Carlton, B. and Segrave, M. (2016) 'Rethinking women's post-release reintegration and 'success”, Australian \& New Zealand Journal of Criminology, 49(2): 281-299.

Corcoran, M. and Fox, C. (2013) 'A bit neo-liberal, a bit Fabian: Interventionist Narratives in a Diversionary Programme for Women', in: B. Carlton and M. Segrave (Eds.), Women Exiting Prison. Critical Essays on Gender, Post Release Support and Survival, London: Routledge.

Correctional Services of Canada (1990) Creating Choices: The Report of the Task Force on Federally Sentenced Women, Ottawa, ON: Women Offender Program and Issues.Available: https:/www.cscscc.gc.ca/women/toce-eng.shtml (accessed 10 November 2018).

Correctional Services of Canada (2010) Revised National Community Strategy for Women Offenders, Ottawa, ON: Women Offender Sector. Available at: http:/www.csc-

scc.gc.ca/publications/fsw/ wos22/wos22-eng.shtml (accessed 10 November 2018).

Corston, B.J. (2007) The Corston Report: A Report of a Review of Women with Particular Vulnerabilities in the CriminalJustice System, London: Home Office. Available at:

https:/webarchive.nationalarchives.gov.uk/+/http://www.homeoffice.gov.uk/documents/corston-

report/ (accessed 30 November 2018).

Easton, H. and Matthews, R. (2010) Evaluation of the 218 Service: Examining Implementation and Outcomes, Edinburgh: Scottish Government. Available at: http://www.turningpointscotland .com/wp-content/uploads/2011/03/218-evaluation.pdf (accessed 3 December 2015).

Gelsthorpe, L., Sharpe, G. and Roberts, J. (2007) Provision for Women Offenders in the Community, London: Fawcett Society. Available at: https:/www.fawcettsocietv.org.uk/provision-forwomen-offenders-in-the-community (accessed 10 December 2018).

Goodkind S (2005) Gender-specific services in the juvenile justice system: A critical examination. Affilia 20(1): 52-70. 
Goodkind, S. (2009) "'You can be anything you want, but you have to believe it": Commercialized feminism in gender-specific programs for girls', Signs 34(2), 397-422.

Hannah-Moffat, K. (2010) 'Sacrosanct or flawed: Risk, accountability and gender-responsive penal politics', Current Issues in Criminal Justice 22(2), 193-215.

Hannah-Moffat, K. and Innocente, N. (2013) 'To thrive or simply survive: Parole and the post-release needs of Canadian women exiting prison', in: B. Carlton and M.Segrave (Eds.), Women Exiting Prison. Critical Essays on Gender, Post Release Support and Survival, Abdingdon: Routledge.

Home Office (2014) Statistics on Women and the Criminal Justice System 2013. A Ministry of Justice publication under Section 95 of the Criminal Justice Act 199, London: Home Office. Available at: https:/www.gov.uk/government/statistics/women-and-the-criminal-justice-system-2013 (accessed 15 November 2015).

Huebner, B.M., DeJong, C. and Cobbina, J. (2010) 'Women coming home: Long-term patterns of recidivism', Justice Quarterly 27(2), 225-254.

Ipsos MORI (2015) An evaluation of the Shine Women's Mentoring Service. Final Report, Edinburgh: Ipsos MORI. Available at: https://www.ipsos-mori.com/ (accessed 12 April 2015).

Keating, C. (2012) Evaluation of the Women and Mentoring Program, Wellington Collingwood Inc.: Effective Change Pty Ltd. Available at: http:/womenandmentoring.org.au/cms/wpcontent/uploads/2014/09/Women-and-Mentoring-Evaluation-Report.pdf (accessed 11 December 2018).

Koschmann, M.A. and Peterson B.L. (2013) 'Rethinking recidivism: A communication approach to prisoner reentry', Journal of Applied Social Science 7(2), 188-207.

Malloch, M., McIvor, G. and Loucks, N. (2008) "Time Out" for Women: Innovation in Scotland in a Context of Change', The Howard Journal, 47(4), 383-99.

Ministry of Justice (2012) Prisoners' childhood and family backgrounds, London: MoJ.

Available at: https://www.gov.uk/government/uploads/system/uploads

_attachment_data/file/278837/prisoners-childhood-family-backgrounds.pdf (accessed 1 March 2016).

Mulholland, C., $\quad$ Eunson, J., $\quad$ Murray, L., $\quad$ Bowen, L., $\quad$ McIvor, G., $\quad$ Malloch, M., $\quad$ Whyte, B., Kirkwood, S. and McNeill, F. (2016) Evaluation of the Reducing Reoffending Change Fund, Edinburgh: Scottish Government Social Research.

Newburn, T. and Shiner, M. (2006) 'Young people, mentoring and social inclusion', Youth Justice, 6(1), 23-41.

Oakley, A. (1981) 'Interviewing women: a contradiction in terms', in: H. Roberts (Ed.) Doing Feminist Research, London: Routledge. 